\title{
A CULTURAL FRAMING OF NATURE: CHINESE TOURISTS' MOTIVATIONS FOR, EXPECTATIONS OF, AND SATISFACTION WITH, THEIR NEW ZEALAND TOURIST EXPERIENCE
}

\author{
JOANNA FOUNTAIN, STEPHEN ESPINER, and XIAOYAN XIE \\ Faculty of Environment, Society and Design, Lincoln University, \\ Canterbury, New Zealand
}

\begin{abstract}
The Chinese holiday market has become very important to the New Zealand tourism industry. Understanding Chinese tourists' needs is therefore crucial for the future development of this market. Existing research suggests that for Chinese visitors, like other market segments, the natural landscape has a strong influence over the decision to travel to New Zealand. There is an emerging concern, however, that the country's tourism product must diversify, and attention is now shifting to utilize the appeal of culture and heritage attractions in New Zealand, particularly Māori cultural products. This article reports on research into Chinese tourists' motivations, expectations, and behavior with respect to their travel in New Zealand. Particular emphasis is given to an exploration of the relative importance of nature and culture to these Chinese tourists. Findings suggest that the Chinese market may be particularly suited to a culturally oriented experience of New Zealand, but one based less on Māori culture as it is often portrayed to tourists (e.g., cultural performances, or experiencing a hangi), and more on the opportunities to learn about Māori stories and legends as part of visiting natural environments. The implications of these findings for shaping the Chinese tourist gaze in New Zealand are discussed.
\end{abstract}

Key words: Chinese tourists; New Zealand; Motivations; Expectations; Nature; Cultural tourism

Introduction

Over the past two decades, outbound tourism demand from mainland China has become an important focus for destination managers and marketers and tourism academics (X. Li, Lai, Harrill, Kline, \& Wang, 2011). The Chinese government's loosening of restrictions on outbound travel since the 1980s has continued with the expansion of the
Approved Destination Status (ADS) scheme. ADS has now been granted to more than 130 countries (Ministry of Tourism, 2010a; Sparks \& Pan, 2008). This relaxation of travel restrictions has been accompanied by swift economic development, which has resulted in a growing middle class with the means and desire to gain first-hand experience of the rest of the world (Arlt, 2006; Ministry of Tourism, 2010). Today China is seen by observers as 
one of the two most important tourist-generating markets worldwide, with the potential to have a massive influence on the marketing of tourism and destination development in coming years (Kim, Guo, \& Agrusa, 2005). Between 1993 and 2002, the average rate of annual growth was $20 \%$ (Kim et al., 2005) and by 2007, outbound travel by Chinese residents had reached 40 million trips annually: a quadrupling in 10 years (Ministry of Tourism, 2009). There has been a corresponding growth in expenditure; in 2005 Chinese nationals spent US\$22 billion on tourism abroad, an increase from US\$3.6 billion 10 years earlier (Arlt, 2006). This growth has slowed somewhat in the past few years; in 2008 visitor numbers dropped slightly as a consequence of the Beijing Olympics and, a few months later, the Sichuan earthquake, while in 2009 the global economic down-turn, and concerns surrounding the influenza A H1N1 (swine flu) pandemic, also affected visitors numbers. Notwithstanding these recent setbacks, the Chinese outbound market was expected to exceed 51 million by 2010 (Ministry of Tourism, 2010).

The Chinese visitor market has become very important to the New Zealand tourism industry, and now represents its fourth largest source of visitors (Ministry of Tourism, 2010). Most tourism by mainland Chinese to New Zealand has occurred since 1999, when New Zealand became one of the first Western counties to be granted ADS status. A simplified passport application process and direct air links between China and New Zealand since 2006 have aided visitation from China. To the year ending June 2010, there were 105,191 Chinese visitors to New Zealand, accounting for approximately $5 \%$ of total annual overseas visitors (Ministry of Tourism, 2010), and forecasts suggest that visitation from China will continue to grow (Ministry of Tourism, 2010).

Given the emerging importance of the Chinese visitor market to New Zealand tourism, it is crucial to understand their expectations of, and satisfaction with, their tourism experience in this country. To date there has been somewhat limited research on this topic, although this is increasing (Becken, 2003; Chan, 2009; Cone, 2005; Mohsin, 2008; Ryan \& Mo, 2001; Tian, 2008; Zhao, 2006; Zhu, 2006). Existing research suggests that for Chinese visitors, like other market segments, the natural landscape has an important influence over the decision to travel to New Zealand (Chan, 2009; Cone, 2005; Zhao, 2006) and that they are reasonably satisfied with their experiences in New Zealand, although levels of satisfaction within the Chinese visitor market to New Zealand is generally lower than that of other markets (Ministry of Tourism, 2010).

The purpose of this research has therefore been to explore Chinese tourists' motivations, expectations, and behaviors, with respect to a range of attractions and activities experienced in New Zealand. The study used a self-complete questionnaire administered to 181 Chinese tourists visiting Queenstown in November 2009. This article reports, in particular, on the relative importance of natural attractions and cultural elements to Chinese tourists during their time in New Zealand.

\section{Literature Review}

Understanding tourists' expectations and preferences when they make travel decisions is fundamental to effective destination management and marketing. Similarly, being aware of how tourists interpret the experiences they encounter, and how these experiences compare with their expectations, provides important insights to tourist satisfaction. Generally, in the consumer behavior literature, customer satisfaction is seen as a function of performance expectations and expectancy disconfirmation (Eagles \& McCool, 2002; Jacobson, 2001; Latu \& Everett, 2000; Oliver, 1980; Parasuraman, Zeithaml \& Berry, 1985), with the general assumption being that "satisfaction increases as the performance/expectation ratio increases" (Oliver, 1980, p 460). Satisfaction arises from the individual's subjective evaluation of an experience, relative to his or her expectation of that involvement (Moore, 1995; Rollins \& Robinson, 2002).

There is growing recognition of the importance of the role of cultural background in determining how expectations are established, how an experience is perceived and explained, and, therefore, how satisfied one is with an experience (Caneen, 2004; Hofstede, 2001; Mok \& DeFranco, 1999; Reisinger \& Turner, 2003). Expectations come from a number of sources, which include the qual- 
ities and perceptions acquired from a particular cultural background (X. Li et al., 2011; Oliver, 1980). How one perceives and assesses a situation will be influenced also by one's cultural background, including the position of one's culture in terms of power distance, individualism, and masculinity dimensions (Chang, 2008; Hofstede, 2001). In this context, therefore, it is important to recognize that "Chinese travellers may have particular travel expectations, preferences, and requirements that are not yet well understood by Western marketers" (X. Li et al., 2011, p. 3).

One useful way to assess satisfaction and some of its associated concepts is the EPI (ExpectationsPerceptions-Importance) approach (Latu \& Everett, 2000). This approach requires respondents to evaluate the importance of some predefined feature or attribute, as well as their perception of the extent to which this feature or attribute met their needs; if the perception of the experience is lower than expectation then this is used as a measure of dissatisfaction. The significance of any discrepancy between perception of the experience and expectation can be established by determining the respondents' assessment of the importance of each feature. The formula for assessing satisfaction in this manner is [(Perception-Expectations)*Importance] (Latu \& Everett, 2000). The EPI methodology can be used as a comprehensive, flexible, and economic way to provide data suitable for management decisions (Espiner, Higham, \& Corbett, 2006).

A number of studies globally have explored the motivations and expectations of travelers from mainland China. What is known is that, as yet, Chinese are relatively inexperienced travelers, who tend to prefer to travel on package tours rather than as independent travelers, and for whom value in their travel experience is very important. This value is sometimes determined on the basis of the number of destinations or sites that can be experienced on one trip, which means overall, Chinese visitors do not spend long in each destination (Becken, 2003; Chan, 2009; Cone, 2005; Guo, Kim, \& Timothy, 2007; Ministry of Tourism, 2009). The preference for package tours also reflects the Chinese market's concern for safety (Kim et al., 2005; Weiler \& Yu, 2006).

In terms of the travel experiences they seek, the key destination attributes for Chinese travelers are reported as being the scenic beauty and natural wonders of the destinations they visit (Cone, 2005; Kim et al., 2005; Weiler \& Yu, 2006). Similarly, research on Chinese visitors to New Zealand suggests the primary reasons for choosing to visit revolve around its natural beauty, scenery, and its "clean and green" and unpolluted environment (Cone, 2005; Ryan \& Mo, 2001; Zhao, 2006), although safety is also an important consideration (Becken, 2003; Coventry, 2008; Ryan \& Mo, 2001).

Most of the studies of the Chinese outbound market suggest the Chinese are interested in experiencing different historical and cultural resources including local customs (Becken, 2003; Kim et al., 2005; X. Li et al., 2011; Weiler \& Yu, 2006), with some researchers suggesting that Chinese tourists place a higher priority on gaining cultural experience than other markets (Caneen, 2004; Kau \& Lim, 2005; Xu, Morgan, \& Song, 2009). There is some evidence that high-end travelers rate experiences of culture and history more highly than the market as a whole (Cone, 2005). Research on Chinese visitors to New Zealand supports this assertion, as an important motivation for their visits is to experience the country's unique culture, history, and customs. While some studies have found experiencing Māori culture to be a significant and satisfying element of Chinese visitors' experience of New Zealand (Ryan \& Mo, 2001), in assessing the attractiveness of various destination attributes of New Zealand to residents of three cities in China, Moshin (2008) found no activity associated with Māori culture appearing in the top 10 list of attributes. This finding, however, may relate as much to a lack of knowledge about the activities as lack of interest.

Studies that examine the activities of Chinese visitors in New Zealand are generally difficult to compare because of the differing ways in which the activity categories are framed. Chan (2009) reports that the main activities undertaken are sightseeing, shopping, visiting historic sites, attending a Māori cultural performance, and visiting a botanical garden. By comparison, Ministry of Tourism data suggest the top activities are walking and trekking, visiting volcanic/geothermal attractions, lookouts, viewing platforms, cultural attractions, and other land-based sightseeing (Ministry of 
Tourism, 2009). Ryan and Mo (2001) report that, during their time in New Zealand, Chinese tourists place a great deal of importance on sightseeing and experiencing new places. They derive satisfaction from sightseeing in nature-based settings (visiting national parks and viewing gardens and farms), cities, and on boat cruises, and enjoy experiencing Māori culture (Ryan \& Mo, 2001). Generally Chinese visitors to New Zealand are more interested in a passive enjoyment of New Zealand's natural scenery: that is, by sightseeing rather than be being actively involved, although younger visitors are more interested in active experiences (Ryan \& Mo, 2001).

Chinese tourists tend to leave New Zealand with lower satisfaction than do visitors from other markets, have the lowest satisfaction ratings for food, beverage, and accommodation, and have significantly lower satisfaction ratings than the "all markets" average for activities undertaken in New Zealand (Ministry of Tourism, 2010). A similar finding is reported of Chinese tourists in Australia (Pan \& Laws, 2001; Weiler \& Yu, 2006). These lower levels of satisfaction have been blamed partly on a tendency in the past for Chinese tour operators to cut costs on food, accommodation, and activities on tours in Australasia, or to prioritize shopping in order to obtain kickbacks (Tourism New Zealand, 2005, 2010; Weiler \& Yu, 2006). Globally, Chinese travelers tend to be influenced by good quality service and tourism facilities, with accommodation, food, and beverage quality and service frequently mentioned as very important (Kim et al., 2005; X. Li et al., 2011; Weiler \& Yu, 2006). The length of most Chinese holidaymakers' trips to New Zealand, for whom the average length of stay was just 5.1 days in 2008 (Ministry of Tourism, 2009), also means, for many Chinese visitors, much of their experience of New Zealand is spent traveling between destinations, or having to visit attractions in a rushed and superficial way, which may reduce satisfaction with the experience (Chen, 2002; Rowan, 2005; see also Weiler \& Yu, 2006). There is also some evidence to suggest that Chinese visitors interpret their New Zealand itinerary as an expensive "add-on" to a trip to Australia, which may negatively affect satisfaction levels (Cone, 2005). The proportion of Chinese visitors traveling to both Australia and New Zealand on a single trip is declining but still represents $77 \%$ of all visitors (Ministry of Tourism, 2010). The lack of satisfaction experienced by this market may also reflect a failure in the industry to understand Chinese visitors' needs fully.

One of the difficulties in most research on Chinese tourists' motivations and activities in New Zealand is a presumption that there is a relatively clear separation between what might be called "natural" and "cultural" activities. For example, a number of studies report an interest by Chinese tourists in the "good natural environment" (Chan, 2009) or the fact that New Zealand is "clean, green, fresh, peaceful" (Zhao, 2006). However, this may reveal a lack of understanding of Chinese culture and philosophy in which such a separation between culture and nature is not straightforward. The definition of a cultural experience for Chinese tourists is not an experience removed from nature, because to them, cultural experiences can be found everywhere, including in wildlife and landscapes. Little tourism literature to date has explored the cultural reasons behind Chinese tourists' expectations and travel decisions, although there are some interesting exceptions to this (Arlt, 2006; F. M. S. Li, 2005, 2008; Mok \& DeFranco, 1999).

The importance of culture to Chinese tourists might be explained by their more than 5,000 years of history, which has created abundant cultural resources for China. However, the close relationship between man and nature comes also from the key principles of Confucianism and Taoist philosophy, described by F. M. S. Li (2005) as "Chinese common knowledge." One of these central principles is the concept of harmony. A basic Confucian assumption is that humans exist in relation to other people, and in relation to nature (Mok \& DeFranco, 1999). In human relationships, this leads to a prioritizing of respect for authority, face, group orientation, and interdependence. In relation to nature, human beings are regarded as part of nature, and a harmonious relationship between nature and humans is central to Chinese culture (F. M. S. Li, 2005). The guiding belief is that "nature without man and man without nature are incomplete" (F. M. S. Li, 2008, p. 499). This might also be expressed as "because nature is imperfect, humans need to improve on it with buildings and 
other constructions in order to create harmony." This means that the Western conception of "wilderness," as unmodified and untouched nature, is foreign to the Chinese mindset, and the concept has rather negative connotations. In other words, to be meaningful to the Chinese, "the physical landscape must be permeated with human cultural and historic heritage" (F. M. S. Li, 2008, p. 501). There must be evidence of a harmonious relationship between man and nature: it must be a "culture-scape" (F. M. S. Li, 2008, p. 494).

Confucius taught that human beings should learn from nature, with people of different characters gaining different knowledge and experience from nature around them (Arlt, 2006). Similarly, Taoism suggests that man should follow nature, integrate with nature, and search for aesthetic values from nature (Arlt, 2006), so the attractiveness of nature is evaluated by its connection with legend, stories, poems, history, or famous people, and not just its natural beauty. For example, F. M. S. Li (2008) reports that many Chinese know the names of about 100 pine trees, which have been made famous through many poems - these are important tourist attractions, but Chinese visitors visit these trees for their cultural value, and not their botanical significance. She reports also that many of the most famous "natural" tourist sites in China are renowned not for their scenic attractions but for their comprehensive links to China's cultural heroes: poets, historical leaders, and so on. She argues that without this cultural validation, many of these sites would not have been developed as tourist destinations. In other words, these differences based on common Chinese knowledge result in a distinctive "Chinese tourist gaze" on nature (F. M. S. Li, 2008).

Clearly, in a New Zealand context, a cultural tourism experience does not exclude the natural environment or vice versa. In fact, a cultural experience can add value to the experience of the country and landscape, and interpretation of New Zealand's natural heritage from a Māori perspective is recognized as offering a unique point of difference for New Zealand tourism operators (Colmar Brunton, 2003; McIntosh, 2004; Molloy, 1993; Wilson et al., 2006). As Carr (2006) states, the "intangible aspects of culturally significant landscape features are often elusive" (p. 83), but visitors may become aware of them through promotional literature, place names, or through interpretation that relates local stories, myths, and history. Increasingly, tourism operators are adding a cultural aspect to interpretation of the natural environment, and Wilson et al. (2006) report that many tourists feel that incorporating historical stories into their New Zealand experience offers a "richer dimension to the experience" (p. 65). The issue at the forefront of the present research is therefore whether Chinese tourist experiences of New Zealand currently satisfy their tendency to desire a cultural framing of nature.

\section{Methodology}

This research project relied on a self-completed survey, conducted with Chinese visitors to Queenstown, a popular tourist destination in the South Island of New Zealand. Queenstown was chosen as the location for data collection due to its importance on the itineraries of Chinese visitors to New Zealand and the fact that it is usually the penultimate destination for Chinese visitors, and therefore a good place for them to reflect on their trip to New Zealand. Respondents were selected by means of convenience sampling in three areas of Queenstown: outside the reception of the Skyline Function Centre, in the Queenstown Mall, and in the cruise harbor. These three places were chosen for their popularity with tourists and because they were all places where tourists might be waiting (to take a cruise, or the Skyline gondola) and therefore had free time (Queenstown Mall). The researcher stationed herself in these locations and approached people of apparent Asian descent, asking each potential respondent an initial question to determine whether they were international tourists from mainland China and within the target age range. Once eligibility was established, the researcher and research project were introduced and participation in the research project sought. Where willingness was confirmed, the respondent was given a copy of the questionnaire to complete. The next respondent was approached once the questionnaire had been accepted by the previous participant.

All data collection took place over a week in November 2009 during daylight hours. Data were 
collected from 181 respondents over 18 years of age who identified themselves as international tourists. Over the sampling period, 272 international tourists were asked to take part in the research, resulting in a response rate of $66.5 \%$.

The survey contained three sections and 19 close-ended questions. Section one focused on general information related to respondents' travel to New Zealand. Section two was more specific about the Chinese tourists' perspective of their experiences in New Zealand. Section three collected respondent profile information, including age and gender. The questionnaire was designed in English and translated into Chinese (Mandarin). The translation was verified by a second Chinese/English speaker and pretested with a small number of Chinese students before implementation in the field. The questionnaire took approximately 5 minutes for each visitor to complete. Data were entered into an Excel spreadsheet before being transferred to SPSS 17 for analysis.

\section{Findings}

\section{Profile of the Sample and Visit Characteristics}

An analysis of age distribution of the sample revealed that respondents were considerably younger than the national average for Chinese visitors as reported in Ministry of Tourism (2009) data (Fig. 1), particularly among the youngest age group, 19-29 years (35.9\%); it should be noted that the national data for this age group excludes 19 year olds. Those aged 60-69 years were also somewhat overrepresented in the sample. The age group most underrepresented was the middle aged (40-59 years).

The gender split of the sample was relatively even (males $48.1 \%$; females $51.9 \%$ ), indicating a slight overrepresentation of females, who constituted $45 \%$ of all Chinese visitors in 2008 (Ministry of Tourism, 2009).

In terms of length of stay, respondents' visits to New Zealand in this study were much longer than the national average. While $79 \%$ of all Chinese visitors to New Zealand stay 1 week or less, just over a quarter of this sample $(28.2 \%)$ were in the country for 1-7 days, with the largest proportion of the sample (37\%) staying between 1 and 2 weeks, and a further $19 \%$ staying between 2 and 3 weeks. Of the $16.1 \%$ of respondents staying for more than 4 weeks, five respondents $(2.8 \%)$ were staying for almost a full year. Excluding these five respondents, the average length of stay for the sample was 13.3 days.

Respondents to this survey were mostly experienced travelers; a third of the sample $(33.1 \%)$ had visited New Zealand before, compared with only $16 \%$ of all Chinese visitors to New Zealand (Ministry of Tourism, 2009).

Table 1 describes the profile of travel parties of the Chinese tourists interviewed in the survey. Half of the respondents $(53.6 \%)$ were traveling with family members or their spouse, and most of the remainder were traveling with friends $(42.0 \%)$. A very small proportion of respondents were ei-

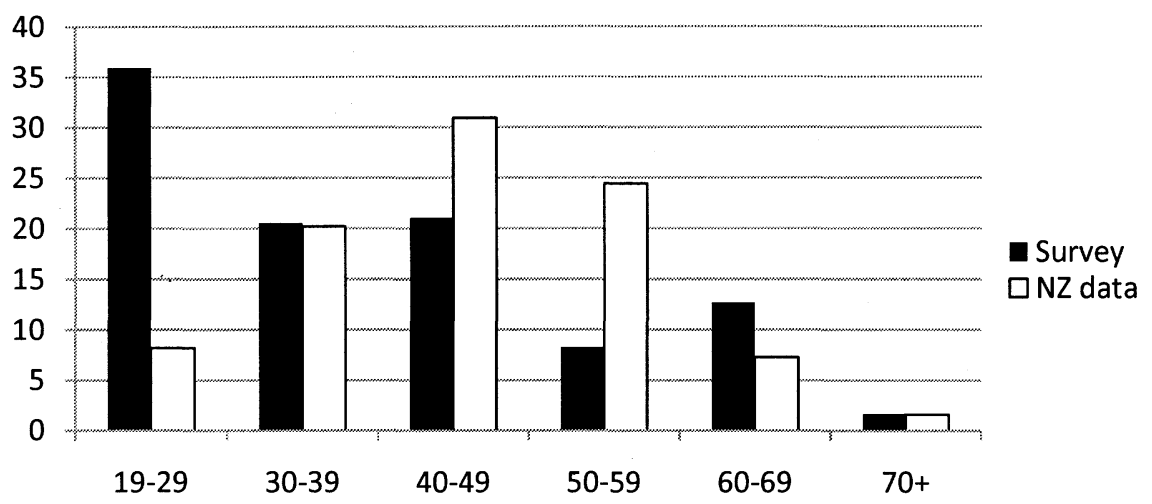

Figure 1. Age of survey respondents compared to Chinese visitors to New Zealand (Ministry of Tourism, 2009). 
Table 1

Travel Party

\begin{tabular}{lrr}
\hline & Freq. & $(\%)$ \\
\hline Traveling alone & 5 & 2.8 \\
Traveling with family/spouse & 97 & 53.6 \\
Traveling with friends & 76 & 42.0 \\
Traveling with business associates & 3 & 1.7 \\
Total & 181 & 100.0 \\
\hline
\end{tabular}

ther traveling alone $(2.8 \%)$ or with business associates $(1.7 \%)$.

More than half of the sample reported that they were traveling independently $(55.6 \%)$ rather than as part of an organized group (44.4\%). The proportion of respondents traveling independently is much higher than among this market as a whole, where approximately $71 \%$ of the total market is traveling in an organized group (Ministry of Tourism, 2009).

Some interesting differences are apparent when the sociodemographic characteristics of respondents traveling independently (FIT) are compared with those respondents traveling in an organized group. While $86.3 \%$ of those on an organized tour were visiting New Zealand for 2 weeks or less, only half of those respondents traveling independently were in the country for 14 days or less, with $21 \%$ staying for 4 weeks or more. Similarly, there were marked differences in the age distribution of those on organized tours versus independent travelers, with those on organized tours generally being the older visitors. Three quarters $(76.9 \%)$ of those under 30 years of age were traveling independently. The age groups most likely to be traveling on organized tours were aged 40-49 years $(65.8 \%)$ and $60-69$ years $(63.6 \%)$.

Respondents were presented with a list of 32 destinations and asked which of the places they had visited on their trip to New Zealand, with a visit defined as a stay in the place for an hour or more. The top 20 responses are listed in Table 2. Given the location of the survey in Queenstown, it is not surprising that most of the top 10 destinations are in the South Island, the exceptions being Auckland and Rotorua. It is interesting to note that of the destinations listed, 13 out the 14 lowest ranked destinations were national parks. Chinese tourists $\mathrm{did}$ visit national parks when they visited some of New Zealand's most iconic attractions, but it seems they may not have been aware of the national park status of the location. For example, while $40.9 \%$ of the Chinese tourists stated they had visited Fiordland National Park (location of Milford Sound, which over half of the respondents said they had visited), less than $1 \%$ mentioned that they had visited Westland National Park (location of the Franz Josef and Fox Glaciers).

In terms of activities engaged in during their visit, over $80 \%$ of respondents stated that they had viewed natural landscapes, shopped, visited a museum, taken a scenic boat cruise, and learned about Māori culture (Table 3). Learning the stories behind nature was an activity reported by just over half of all respondents $(54.1 \%)$, while naturebased adventure activities, such as hiking, mountain biking, horse trekking, and bungee jumping, generally ranked much lower.

\section{Motivations, Expectations, and Satisfaction}

In order to understand the destination attributes that motivated them to visit, respondents were presented with a list of features of potential relevance to New Zealand as a tourist destination and asked to rank how important each one was in their decision to travel to New Zealand. A scale was used

Table 2

Destinations Visited in New Zealand

\begin{tabular}{lrr}
\hline & Freq. & $\%$ \\
\hline Queenstown & 181 & 100.0 \\
Christchurch & 173 & 95.6 \\
Auckland & 160 & 88.4 \\
Rotorua & 109 & 60.2 \\
Franz Josef or Fox Glacier & 92 & 50.8 \\
Milford Sound & 91 & 50.3 \\
Lake Tekapo & 77 & 42.5 \\
Fiordland National Park & 74 & 40.9 \\
Dunedin & 63 & 34.8 \\
Hanmer Springs & 63 & 34.8 \\
Mt Cook & 62 & 34.3 \\
Wellington & 57 & 31.5 \\
Kaikoura & 55 & 30.4 \\
Akaroa & 50 & 27.6 \\
Lake Wanaka & 46 & 25.4 \\
Lake Taupo & 33 & 18.2 \\
Waikato & 25 & 13.8 \\
Greymouth & 12 & 6.6 \\
Arthurs Pass National Park & 6 & 3.3 \\
Hawkes Bay & 6 & 3.3 \\
\hline
\end{tabular}


Table 3

Activities Engaged in While in New Zealand

\begin{tabular}{lrr}
\hline & Freq. & $\%$ \\
\hline Viewing natural landscapes & 178 & 98.3 \\
Shopping & 171 & 94.5 \\
Visiting museum & 161 & 89.0 \\
Scenic boat cruise & 156 & 86.2 \\
Learning about Māori culture & 150 & 82.9 \\
Learning stories behind nature & 98 & 54.1 \\
Visiting historical sites & 91 & 50.3 \\
White water rafting & 67 & 37.0 \\
Traditional Māori feast & 67 & 37.0 \\
Viewing dolphins or whales & 62 & 34.3 \\
Hiking & 33 & 18.2 \\
Horse trekking & 30 & 16.6 \\
Bungee jumping & 23 & 12.7 \\
Mountain biking & 18 & 9.9 \\
Learning facts about native plants and birds & 16 & 8.8 \\
\hline
\end{tabular}

on which 1 was "not important at all" and 7 was "very important" (see Fig. 2). The two most important reasons for Chinese traveling to New Zealand were "natural scenery" (6.52) and "New Zealand's clean and green image" (6.44); these responses were clearly more popular than any other reasons. The "stories behind nature" (4.99), "wildlife" (4.69), and "Māori culture" were the only other responses to have a mean of over 4 (neutral), with adventure sport (2.62) and Chinese heritage (2.6) being the lowest rated reasons for traveling to New Zealand.
Respondents were asked what they expected to experience during their time in New Zealand, and to rank a number of potential experiences on a scale where 1 was "strongly disagree" and 7 was "strongly agree." Expectation generally relates to previous knowledge or marketing and promotion of a place, although expectations can change based on actual travel experiences. For this reason, respondents were asked about the importance of certain aspects of this trip to them, reflecting actual experience, rather than prior expectation, and then asked to rate these on a scale on which 1 was "not important at all" and 7 was "very important." Respondents were also asked how satisfied they had been with these same aspects of their experience, on a scale where 1 was "very dissatisfied" and 7 was "very satisfied." These results are presented in Table 4.

"Viewing New Zealand's nature" was clearly the most expected aspect of their trip to New Zealand, recording the highest importance and satisfaction levels. Interestingly, "learning the stories behind New Zealand's landscape" was the second highest expectation, and became more important during their trip, although satisfaction with this aspect of their experience was particularly low; the only satisfaction level rating lower was "learning about the history and stories of New Zealand wildlife." By comparison, the lowest expectations of

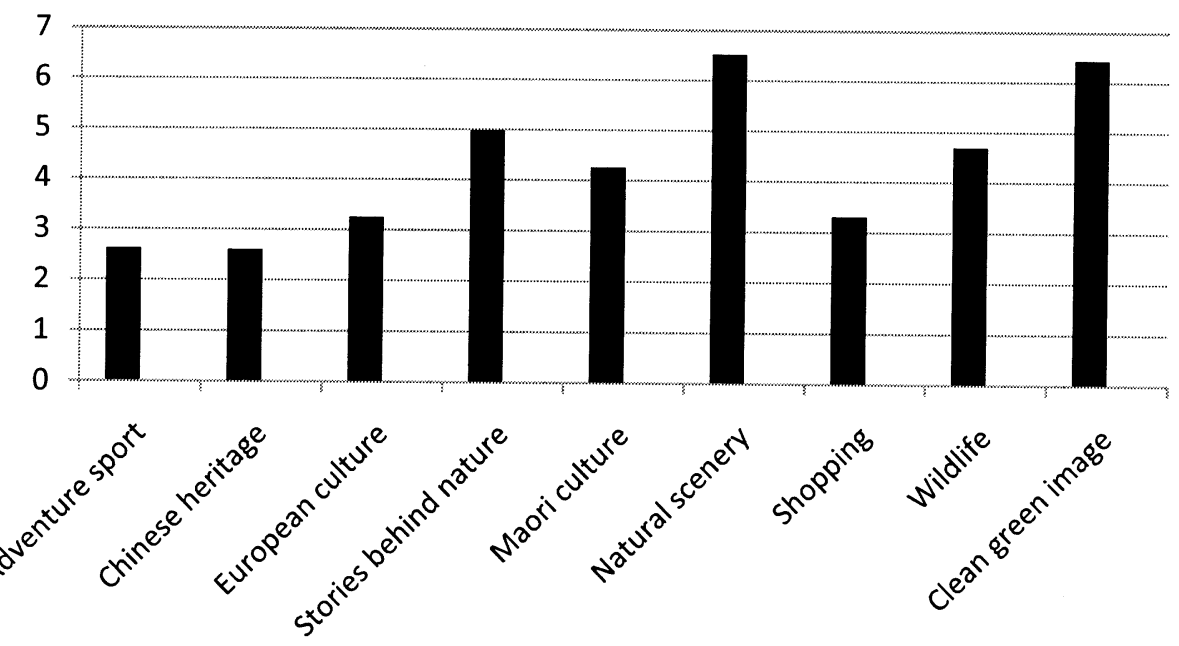

Figure 2. Reasons for visiting New Zealand. 
Table 4

Comparison Between Expectation, Importance, and Satisfaction With Activities

\begin{tabular}{lcccc}
\hline & $\begin{array}{c}\text { Expectation } \\
\text { Mean }\end{array}$ & $\begin{array}{c}\text { Importance } \\
\text { Mean }\end{array}$ & $\begin{array}{c}\text { Satisfaction } \\
\text { Mean }\end{array}$ & $\begin{array}{c}\text { Gap Score } \\
{[(\mathrm{S}-\mathrm{E}) * \mathrm{I}]}\end{array}$ \\
\hline Learn about New Zealand Māori history and culture & 3.23 & 4.42 & 5.13 & +8.40 \\
Experience New Zealand Māori cultural practices & 3.10 & 4.33 & 5.02 & +8.31 \\
View wildlife in its natural habitat & 4.10 & 4.89 & 4.87 & +3.77 \\
Viewing New Zealand's nature & 6.57 & 6.67 & 6.56 & -0.07 \\
Learn about history and stories of New Zealand wildlife & 4.28 & 5.01 & 4.50 & +1.10 \\
Learn stories behind New Zealand's landscape & 5.20 & 5.96 & 4.81 & -2.32 \\
Learn about New Zealand European history and culture & 3.48 & 3.82 & 5.17 & +6.46 \\
Experience New Zealand European cultural practices & 3.49 & 3.83 & 5.18 & +6.47 \\
\hline
\end{tabular}

respondents' trips to New Zealand related to Māori culture-“learning about New Zealand Māori history and culture" (mean 3.23) and "experiencing New Zealand Māori cultural practices" (mean 3.10) were somewhat unexpected features of their trips, but grew in importance during the trip, and scored relatively high satisfaction ratings.

Gap analysis is a tool that can help compare tourism products in terms of actual and potential performance. It is used in this study to analyze the gap between the expectation and importance of eight attributes and respondents' perceptions of the performance of each. This analysis reveals that the two measures of Māori culture had the most positive gap score, followed by the two measures of learning about and experiencing New Zealand European history and culture. The only gap score that was clearly negative, suggesting expectations had not been met, related to the highly important attribute "learning stories behind New Zealand's landscape."

The difference between expectation, importance, and satisfaction is revealed graphically in Figure 3, where 1 on each measure is the most negative response, and 7 is the most positive response. This figure reveals high expectation and even higher importance ratings, but much more moderate responses on satisfaction. By comparison, on the attributes "learn about Māori history and culture" (Fig. 4) and "experience New Zealand Māori cultural practices" (Fig. 5) expectations were generally low, while importance was moderate and satisfaction high.

\section{Discussion}

Findings of this research support those of previous studies suggesting that the main reasons for
Chinese traveling to New Zealand are the destination's natural scenery and clean, green image (Chan, 2009; Cone, 2005; Ryan \& Mo, 2001). This reflects the motivations of most of the country's international visitors, $90 \%$ of whom chose New Zealand as a holiday destination due the natural landscape and scenery (Colmar Brunton, 2003).

In terms of their New Zealand experience, it seems that, generally, these particular Chinese visitors were very satisfied with their experience of the natural scenery, and viewing natural landscapes constituted an important element of their experiences; virtually all respondents stated that they had viewed natural landscapes during their trip, and $86 \%$ reported that they had taken a scenic boat trip. Given their desire to view natural scenery, it is interesting to note that the top four destinations visited were urban centers and, apart from visits to New Zealand's iconic sites such as Aoraki/Mt Cook and Milford Sound, there was little visitation to national parks around the country.

New Zealand's culture and history was not reported as an important reason for visiting the country among this sample, in contrast to previous studies (Cone, 2005; Ryan \& Mo, 2001). "Māori culture" ranked higher than "European culture" as a reason for visiting, but was still relatively unimportant, and neither type of cultural experience was an expected outcome for these tourists. Having said this, it is clear that, during their trip to New Zealand, experiencing and learning about both Māori and European culture grew in importance, with a museum visit and learning about Māori culture being experienced by over $80 \%$ of respondents. Furthermore, satisfaction levels with cultural experiences were higher than for all other 


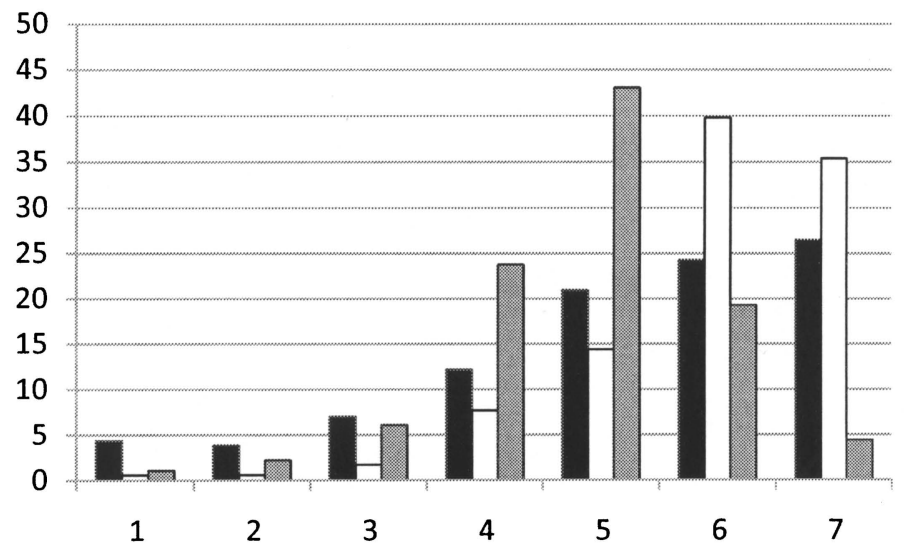

expectation $\square$ Importance $\square$ satisfaction

Figure 3. Learning stories behind New Zealand's landscapes.

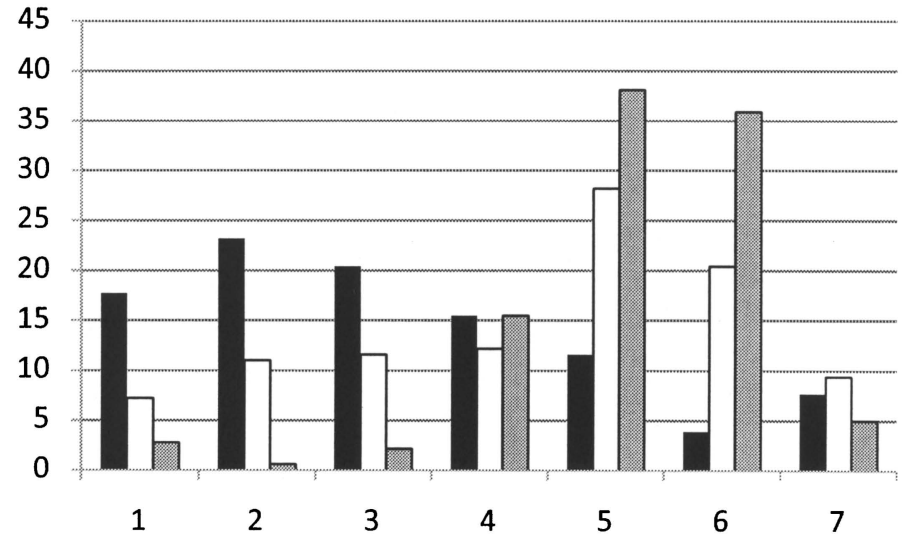

Figure 4. Learning about Māori history and culture.

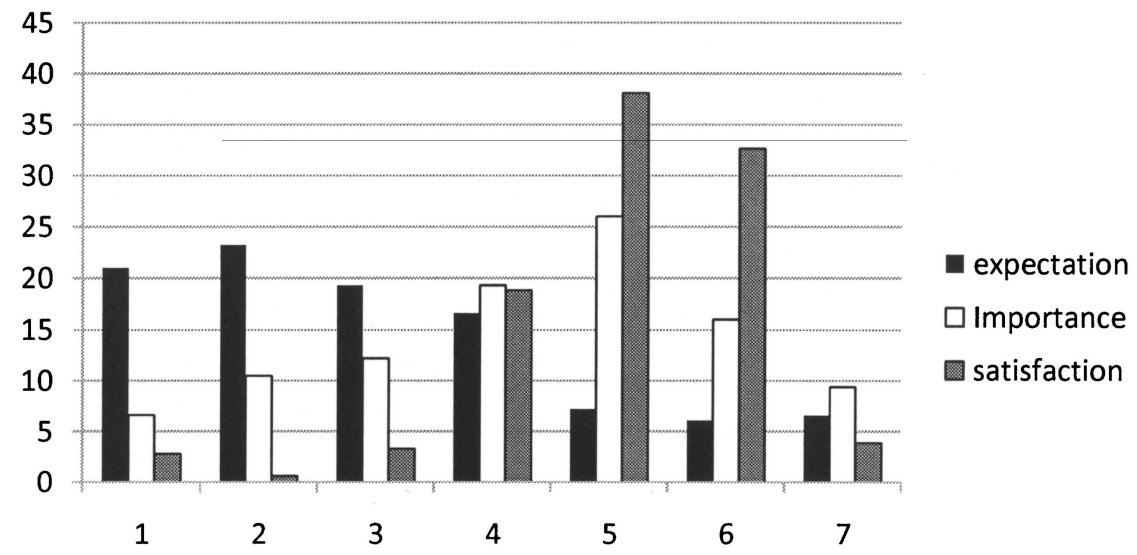

Figure 5. Experiencing New Zealand Māori cultural practices. 
experiences apart from viewing natural scenery. This reflects the fact that satisfaction can be based on positive yet unexpected outcomes, as much as on expectations alone (Bowen \& Clarke, 2002). These findings suggest that these Chinese tourists may have had little knowledge about the culture of New Zealand before visiting, a finding reported elsewhere (Mohsin, 2008). Given their obvious satisfaction with this aspect of their visit, more publicity and promotion of the history and culture of New Zealand, both European and Māori, by Tourism New Zealand and tour operators seems warranted.

One aspect that has not been studied in relation to Chinese tourists' experience of New Zealand in the past is the degree to which New Zealand's natural landscapes are connected to the culture of the place, and in particular the stories, histories, myths, and legends. As already stated, an important element of common Chinese knowledge is the connection between nature and culture in Chinese philosophy, and the sense that landscape without culture is incomplete (F. M. S. Li, 2008). While the Chinese visitors in this study expressed high levels of satisfaction with their experiences of viewing natural scenery, and appeared satisfied with their experiences of New Zealand European and Māori culture, the tourist product Chinese tourists are offered may lack a connection between the "nature" they are experiencing and the "culture" they expect. This is evident in respondents' evaluations, revealing generally low levels of satisfaction for "learning the stories behind New Zealand's landscape" — ranked by respondents as the third highest reason for choosing New Zealand as a tourist destination and second highest for expectation of what they would experience during their trip. Only about half of the respondents $(54.1 \%)$ reported that they were able to learn "the stories behind New Zealand's landscape," and this experience scored one of the lowest levels of satisfaction-the only category rating lower was "learning stories about wildlife." This apparent deficiency in clearly imparting the "stories behind nature" (landscape and wildlife) appears to offer an important opportunity for the New Zealand tourism industry.

The opportunity to provide deeper connections between nature and culture must also be acknowl- edged by New Zealand's Department of Conservation (DOC). In the past, DOC, as the formal steward of more than $30 \%$ of New Zealand's terrestrial area, and responsible for the management and administration of most natural attractions (including New Zealand's 14 national parks), has favored natural heritage interpretation emphasizing geological and ecological processes (Molloy, 1993). Without a more obvious cultural dimension, such emphases may not be attractive to, or relevant for, the Chinese tourist gaze. Active engagement with the "culture-scape" of these natural resource areas through interpretation, and more publicity about the nature-culture interaction, may add greater appeal for this market. While nature and natural areas remain strong attractions for visitors, there is growing recognition of the need to diversify New Zealand's tourism product beyond the "clean green" image to further realize the potential of cultural tourism.

The New Zealand Tourism Strategy 2015 highlights scope for growth of Māori tourism opportunities, asserting that "Māori culture provides a distinctive element" which, combined with our natural attractions, "gives New Zealand its unique position as a tourist destination" (Ministry of Tourism, 2007, p. 20; also see McIntosh, 2004). A secondary motivator for $40 \%$ of international visitors to New Zealand is the desire to experience the culture and history of the country, with much of this interest focused on Māori cultural products (AC Neilson, 2002, cited in Wilson et al., 2006, p. 8). Findings in this study suggest that more efforts to connect New Zealand's culture and history-both Māori and Pakeha-to the natural landscape could strengthen the experiences of Chinese visitors to the country. This could take the form of telling more stories about the human history of connection to the natural settings as well as embedding more of the Māori myths and legends in cultural visits, to provide a "richer dimension to the experience" of landscape (Wilson et al., 2006, p. 65). Stakeholders in New Zealand's tourism industry may wish to identify appropriate ways to engage meaningfully with Chinese visitors in order to maximize the benefits associated with an emergent tourist segment with considerable growth potential. 


\section{Conclusion}

This research is based on a sample of Chinese tourists in Queenstown, which is likely to differ in a number of ways from the wider Chinese visitor market in New Zealand. In summary, the sample reported here is made up of respondents who are younger, more likely to be traveling independently, and who spent longer in the country than is typical of the Chinese market as a whole. The extent to which these findings reflect the motivations and experiences of all Chinese visitors to New Zealand could be explored by undertaking a national survey of the market. Qualitative research with Chinese visitors might also provide a more comprehensive understanding of gaps in the existing New Zealand tourist product and further opportunities to provide a cultural framing of nature for this market.

\section{References}

Arlt, W. G. (2006). China's outbound tourism. New York: Routledge.

Becken, S. (2003). Chinese tourism to New Zealand: Discussion paper. Landcare Research, Lincoln, New Zealand. Retrieved from http://www.landcareresearch. co.nz/research/sustainablesoc/tourism/documents/Chinese tourism.pdf

Bowen, D., \& Clarke, J. (2002). Reflections on tourist satisfaction research. Journal of Vacation Marketing, 8, 297-308.

Caneen, J. M. (2004). Cultural determinants of tourist intention to return. In G. I. Crouch (Ed.), Consumer psychology of tourism, hospitality and leisure (pp. 267275). London: CABI Publishing.

Carr, A. (2006). Lakes, myths and legends: The relationship between tourism and cultural values for water in Aotearoa/New Zealand. In C. M. Hall \& T. Harkonen (Eds.), Lake tourism: An integrated approach to lacustrine tourism systems (pp. 83-97). Ontario, Canada: Cromwell Press.

Chan, D. (2009). Sustainable tourism in New Zealand: The Chinese visitors' view. A Master of Tourism Management report prepared for the Ministry of Tourism Research Scholarship. Victoria University, Wellington. Retrieved from http://www.tourismresearch.govt.nz/Doc uments/Scholarships/ScholarshipReport_DianaChan.pdf

Chang, J. C. (2008). Tourists' satisfaction judgments: An investigation of emotion, equity and attribution. Journal of Hospitality and Tourism Research, 32, 108-134.

Chen, J. (2002). Tour group and independent travel: An analysis of Asian Chinese visitors to New Zealand. Unpublished master thesis, Victoria University, Wellington.
Colmar Brunton. (2003). Demand for cultural tourism. Final research report prepared for TNZ, Wellington, New Zealand.

Cone, M. (2005). The market for Chinese external tourism: The case for New Zealand. Prepared for NZTE. Asia Institute Research Series No. 3. University of Otago, Dunedin, New Zealand.

Coventry, N. (2008, 28 Nov). Tips on maturing China market, which now wants different options ... Inside Tourism, p. 9. Retrieved 13th August, 2010, from http://www. insidetourism.com/pdfpages/pdfs/IT717.pdf

Eagles, P., \& McCool, S. (2002). Tourism in national parks and protected areas: Planning and management. Wallingford, UK: CABI.

Espiner, S. R., Higham, J., \& Corbett, R. (2006). Determining indicators of quality outdoor recreation: A review of social impact monitoring and its application to conservation land management in New Zealand. Wellington: Department of Conservation.

Guo, Y., Kim, S. S., \& Timothy, D. J. (2007). Development characteristics and implications of Mainland Chinese outbound tourism. Asia Pacific Journal of Tourism Research, 12(4), 313-332.

Hofstede, G. (2001). Culture's consequences: International differences in work-related values (2nd ed.). Thousand Oaks, CA: Sage.

Jacobson, S. K. (2001). Monitoring public satisfaction in an ecosystem management framework. Journal of Park and Recreation Administration, 19(4), 83-101.

Kau, A. K., \& Lim, P. S. (2005). Clustering of Chinese tourists to Singapore: An analysis of their motivations, values and satisfaction. International Journal of Tourism Research, 7, 231-248.

Kim, S. S., Guo, Y., \& Agrusa, J. (2005). Preference and positioning analyses of overseas destinations by mainland Chinese outbound pleasure tourists. Journal of Travel Research, 44, 212-220.

Latu, T. M., \& Everett, A. M. (2000). Review of satisfaction research and measurement approaches. Science and Research Internal Report, 183, Department of Conservation, Wellington.

Li, F. M. S. (2005). Chinese common knowledge, tourism and natural landscapes. Gazing on 'Bie you tian di''An altogether different world.' Unpublished Ph.D. thesis. Murdoch University, Perth, Australia.

Li, F. M. S. (2008). Culture as a major determinant in tourism development of China. Current Issues in Tourism, 11, 492-513.

Li, X., Lai, C., Harrill, R., Kline, S., \& Wang, L. (2010). When east meets west: An exploratory study on Chinese outbound tourists' travel expectations. Tourism Management, 32(4), 741-749.

McIntosh, A. J. (2004). Tourists' appreciation of Maori culture in New Zealand. Tourism Management, 25, 1-15.

Ministry of Tourism. (2007). New Zealand Tourism Strategy, 2015. Wellington, New Zealand: Author.

Ministry of Tourism. (2009). Tourism sector profile: China. Retrieved from http://www.tourismresearch.govt. 
nz / Documents / International \% 20Market \% 20Profiles / China\%20Profile.pdf

Ministry of Tourism. (2010). Market and statistics: China. Retrieved from http://www.tourismnewzealand.com/ markets-and-stats/north-asia/china

Mohsin, A. (2008). Analysis of Chinese travellers' attitudes toward holidaying in New Zealand: The impact of socio-demographic variables. Journal of Hospitality Marketing and Management, 16, 21-40.

Mok, C., \& DeFranco, A. L. (1999). Chinese cultural values: Their implications for travel and tourism marketing. Journal of Travel and Tourism Marketing, 8, 99114.

Molloy, L. (1993). The interpretation of New Zealand's natural heritage. In C. M. Hall \& S. McArthur (Eds.), Heritage management in New Zealand and Australia (pp. 59-70). Auckland, New Zealand: Oxford University Press.

Moore, K. (1995). Understanding the individual recreationist; from motivation to satisfaction? In P. J. Devlin, R. A. Corbett, \& A. J. Peebles (Eds.), Outdoor recreation in New Zealand. Vol. 1. A review and synthesis of the research literature. Wellington, New Zealand: Department of Conservation.

Oliver, R. L. (1980). A cognitive model of the antecedents and consequences of satisfaction decisions. Journal of Marketing Research, 17, 460-469.

Pan, G. W., \& Laws, E. (2001). Tourism marketing opportunities for Australia in China. Journal of Vacation Marketing, 8, 39-48.

Parasuraman, A., Zeithaml, V. A., \& Berry, L. L. (1985). A conceptual model of service quality and its implications for future research. Journal of Marketing, 49, 41-50.

Reisinger, Y., \& Turner, L.W. (2003). Cross-cultural behaviour in tourism: Concepts and analysis. Oxford, UK: Butterworth-Heinemann.

Rollins, R., \& Robinson, D. (2002). Conservation and protected areas. In P. Dearden \& R. Rollins (Eds.), Parks and protected areas in Canada: Planning and management (2nd ed., pp. 117-147). Don Mills, ON, Canada: Oxford University Press.

Rowan, J, (2005, July 29). Cheap tours for Chinese a worry. Retrieved August 16, 2010, from http://www. nzherald.co.nz/travel/news/article.cfm?c_id=7\&objectid $=10338055$

Ryan, C., \& Mo, X. Y. (2001). Chinese visitors to New Zealand-demographics and perceptions. Journal of Vacation Marketing, 8, 13-27.

Sparks, B., \& Pan, G. W. (2008). Chinese outbound tourists: Understanding their attitudes, constraints and use of information sources. Tourism Management, 30, 483494.

Tian, F. S. (2008). Is Auckland ready for Chinese travellers? An analysis of Chinese tourists' urban destination requirements and Auckland's capability to provide them. A Master of Business report prepared for the Ministry of Tourism Research Scholarship. Retrieved from http://www.tourismresearch.govt.nz/Documents/Schol arships/SabrinaTian \% 20-\% 20Chinese \% 20tourists \% 27 $\%$ 20urban \% 20destination \% 20requirements \% 20\&\%20 Auckland.pdf

Tourism New Zealand. (2005, May). Keeping them happy. Tourism News, 10-11.

Tourism New Zealand. (2010, June 2). Changes set to benefit Chinese group tour market. Retrieved 13th August, 2010 from http://www.tourismnewzealand.com/newsand-features/latest-news/2010/06/changes-set-to-bene fit-chinese-group-tour-market/

Weiler, B., \& Yu, X. (2006). Understanding experiences of Chinese visitors to Victoria, Australia. Technical report. CRC for Sustainable Tourism, Australia. Retrieved from http://www . crctourism. com.au/wms/upload/Resources/ bookshop/Weiler_ChineseVisitors-VIC.pdf

Wilson, J., Horn, C., Sampson, K., Doherty, J., Becken, S., \& Hart, P. (2006). Demand for eco-cultural tourism. Landcare Research Science Series No. 31. Canterbury: Manaaki Whenua Press.

Xu, F., Morgan, M., \& Song, P. (2009). Students' travel behaviour: A cross-cultural comparison of UK and China. International Journal of Tourism Research, 11, 255-268.

Zhao, C. C. (2006). Tourism research summary report: Chinese outbound market and New Zealand's destination image. Retrieved from http://www.tourismresearch. govt.nz/Documents/Scholarships/ChengchengZhaoChi neseoutboundmarketandNZdestinatio.pdf

Zhu, Y. J. (2006). The potential of the Chinese market for New Zealand tourism: Chinese tourists and Chinese heritage in New Zealand. Unpublished report, Lincoln University, Lincoln, New Zealand. 